\title{
ASSESSING WIND DAMAGE RISK IN COMPLEX TERRAIN USING AN AERODYNAMIC MODEL IN ACACIA HYBRID PLANTATIONS IN QUANG TRI, VIETNAM
}

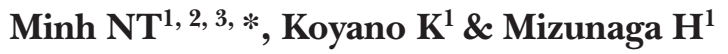 \\ ${ }^{1}$ Faculty of Agriculture, Shizuoka University, 836 Ohya, Suruga-ku, Shizuoka-shi, 422-8529, Japan \\ ${ }^{2}$ The United Graduate School of Agriculture, Gifu University, 1-1 Yanagido, Gifu-shi, 501-1193 Gifu, Japan \\ ${ }^{3}$ Vietnam National University of Forestry, Xuan Mai, Chuong My, Ha Noi, 100000 Vietnam \\ *minhnguyen1408@gmail.com
}

Submitted December 2000; accepted January 2021

\begin{abstract}
Wind damage to both forest plantations and natural forests is a serious concern for forest owners and managers across the world. In this paper, stand attributes (the dominant height of a stand, stand age, soil type and soil depth) and wind properties (wind speed) in a complex terrain were combined to provide wind hazard assessment. The damage to Acacia hybrid plantations was analysed by applying logistic regression models in R-software and using satellite images (LANDSAT-8) combined with airflow simulation (RIAMCOMPACT), to explore the effects of contributing factors in a wind hazard model after Typhoon Doksuri hit on Quang Tri, Vietnam. The results highlighted that the probability of damage is related to increasing tree height of stands and slope $(\mathrm{p}<0.05)$, and wind speed. The hazard ratio regarding wind damage is also governed by soil type $(\mathrm{p}<0.05)$. A growth height curve and site index map were also developed with high accuracy (91and 87.9\%, respectively) for all Acacia plantations in Quang Tri, Vietnam. The results would be helpful to understand the interaction between wind damage and stand attributes, providing a fluid model of predicting wind condition and wind risk in a complex topography region.
\end{abstract}

Keywords: Wind hazard assessment, Acacia hybrid plantation, complex terrain, airflow simulation

\section{INTRODUCTION}

The disturbances caused by strong wind play a major role in forest ecosystems by changing the stand dynamics. These disturbances cause direct damage to trees, loss of timber resources in terms of reduction in carbon storage, and loss of other ecosystem services (Gardiner et al. 2013). Climate change is expected to cause a higher frequency of severe wind disturbances in forest ecosystems on a global scale (Seidl et al. 2016). The high-resolution climate projections for Vietnam predicted a decrease in tropical cyclones over the country from 2045, but with a larger proportion of high-speed wind events (Nguyen et al. 2014). Hence, forest trees will experience higher wind speed pressure and wind damage may occur more frequently. Therefore, it is necessary to establish a damage risk model to develop effective management strategies for sustainable forest management. No studies have modeled wind risk in Acacia hybrid plantation forests under actual strong wind conditions. In Vietnam, Acacia hybrid species are the predominant plantation species with a total area of 1.0 Mha (Do 2020). Acacia plantation areas also have experienced significant impacts from highspeed winds, especially in central Vietnam. For example, in 2017, Acacia plantations accounted for nearly $61 \%$ of the total plantation forest area damaged by Typhoon Doksuri in Quang Tri, reported by the Forest Protection Department (FPD).

The models that aim to predict wind damage in forests can be categorised as empirical, statistical and mechanistic models (Kamimura et al. 2007). Empirical and statistical models are commonly used to help determine key factors of wind damage based on observation datasets and provide accurate wind risk assessment in different regions through one or more high-wind-speed events or temporary plots (Kamimura et al. 2013, Mitchell 2013, Chirici et al. 2018). These models can predict the risk of damage on individual trees, with high accuracy, during high-wind-speed events (Valinger \& 
Fridman 2011). To date, however, finding a powerful and accurate model to assess the risk of wind damage is challenging because of the complex interactions of factors affecting tree stability, and the lack of wind profiles at different spatial scales from stand to landscape.

The probability of wind damage to a tree is affected by the interaction between the tree's vulnerability and wind pressure. To date, few studies have used airflow models for statistical analysis of wind disturbance, although some mechanistic models have integrated wind profile parameters. In Europe, for example, mechanistic models such as GALES and HWIND have been developed to analyse wind hazard risks, with an airflow model of Wind Atlas and Application Programme (WAsP) (Peltola et al. 1997, Gardiner \& Quine 2000). However, it is difficult to use WAsP for steep and complex terrain because WAsP uses a linear model to calculate wind profiles, thus having low accuracy on complex topography. Kamimura et al. (2007) claimed that considering both the terrain and unique topographic effects on wind conditions is required in any analysis of wind disturbance in a complex terrain. Computational aerodynamic models such as RIAM-COMPACT, adapted for complex topography at mesoscale could be effective in understanding wind damage (Uchida 2008). Therefore, linking them to statistical models is a useful initiative to improve assessment of wind damage risk in mountainous areas, and to develop a wind hazard model.

In this study, analysis of data on regional scale wind damage in a Acacia hybrid plantation forest under FPD's management is presented using an empirical method. The main objectives of the study were: i) to examine the efficiency of using a fluid model in complex topography in evaluating wind hazard model by identifying the most important predictor variables for statistical modeling of the probability of wind risk, in a case study in Quang Tri, Vietnam; and ii) to provide a GIS-based area-wide quantification of the probable risk of wind damage for forest managers. The research on integrated GIS, aerodynamics and satellite image analysis to establish a logistic model to clarify affected factors, and to determine wind hazard for $A$. hybrid plantations is the first such approach in Vietnam. The wind damage probability is intended to support decision making in silviculture.

\section{MATERIALS AND METHODS}

\section{Research site}

The research was conducted in Quang Tri Province, Vietnam $\left(16^{\circ} 51^{\prime} \mathrm{N}, 106^{\circ} 51^{\prime} \mathrm{E}\right)$, in which, the terrain becomes increasingly complex from coastal line to the Truong Son Mountains. This area is influenced by subtropical monsoon climate, with mean annual precipitation of 1500 $2200 \mathrm{~mm}$, and mean annual temperature of 22$28{ }^{\circ} \mathrm{C}$. The area of interest measures $10 \times 10 \mathrm{~km}^{2}$ with an elevation ranging from $37-550 \mathrm{~m}$ (Figure 1). Among its various soil types, yellow soil (Ferralsols - F) is the dominant one. The Acacia hybrid plantation forests, owned by FPD and the local government for environmental protection and wood production, covers an area of 4780 ha ( $44 \%$ of total land cover). The study area is also the most affected are by typhoons and tropical storms (5-8 per annum) in Vietnam (Wang et al. 2017).

\section{Data sources}

Two types of sample plots were used to estimate the tree height of Acacia plantations: i) Acacia hybrid plots (95 sample plots) inherited from the Forest Inventory and Planning Institute (FIPI) in 2017, and ii) survey data (15 sample plots) collected from October to November 2017 after Typhoon Doksuri hit. Total number of trees in each sample plot is $460-2100$ trees with a sample size of $1000 \mathrm{~m}^{2}$. Both data types consist of tree height $(\mathrm{H})$, stem diameter at breast height (DBH, $1.3 \mathrm{~m}$ ), stand age (A) and geographic coordinate of the sample plot for each stand.

A spatial dataset with soil type (soil name) and depth was obtained from the National Institute of Agricultural Planning and Projection (NIAPP), Ministry of Agriculture and Rural Development of Vietnam. This dataset was stored in the ArcGIS software (ESRI 2003).

For analysis of wind conditions, a raster Digital Elevation Model (DEM), provided by FIPI, was used with a pixel size of $30 \times 30 \mathrm{~m}$ resolution. Variables describing the topographic characteristics were calculated using ArcGIS Spatial Analyst extension, including slope (Slo), elevation (Elv), azimuth (Az) and the concavity and convexity of a pixel.

LANDSAT-8 was selected to classify damage or undamaged Acacia hybrid plantation forest 


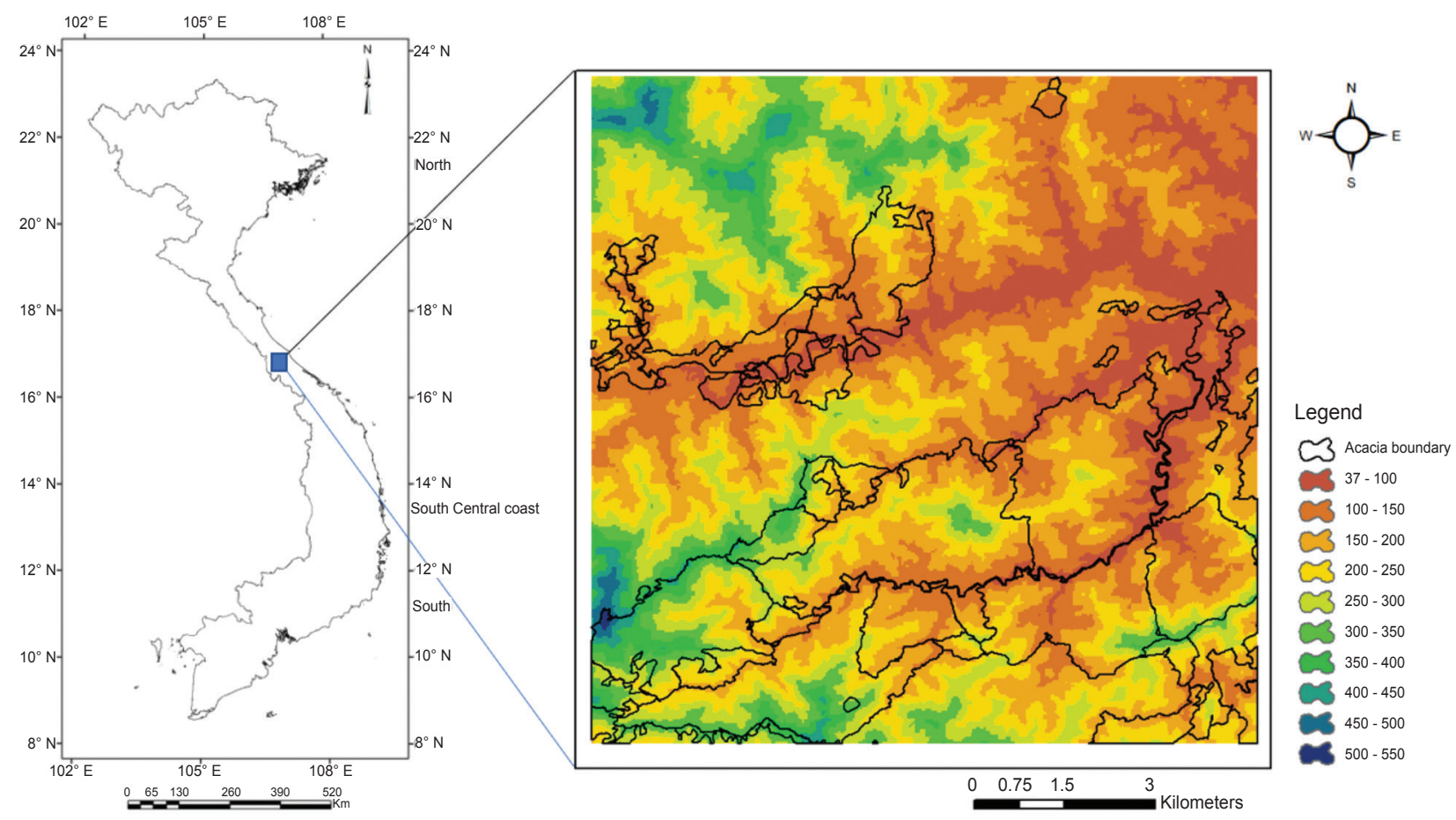

Figure 1 Location of the research site in Vietnam (a) and the distribution of Acacia hybrid plantation forests in relation to elevation (color range, $\mathrm{m}$ ) (b)

in the research site. These images, with GeoTIFF output format, were from Universal Transverse Mercator map projection and World Geodetic System 84 datum (https://earthexplorer.usgs. gov/). Two satellite images, LC08_L1TP_12504 8_20170606_20170616_01_T1 (before typhoon occurred) and LC08_L1TP_125048_20180422_ 20180502_01_T1 (after typhoon occurred) were used (Appendix 1).

In this study, classification as damaged or undamaged forest stands were carried out by interviewing the FPD staff, government staff and the local people. In total, 76 forest patches were defined in July 2018, in which, a damaged area was considered detected when trees in forest patches were broken, knocked over or bent by the storm. Minimum proportion of damaged trees, based on the interview, was estimated as 10 percent of a stand.

\section{Data processing}

As shown in Figure 2, there were four main data processing: i) tree height estimation to predict the dominant height $\left(\mathrm{H}_{\mathrm{dom}}\right)$ (the mean of the highest $20 \%$ of trees in sample plots) of Acacia hybrid stands, ii) prediction of wind properties via RIAM-COMPACT, iii) estimation of wind damage locations by classifying LANDSAT-8 images, and iv) establishing wind risk model for Acacia hybrid plantations. The pulling experiment was also conducted for Acacia hybrid to investigate soil effect on the stability of the species planted in different soil types.

\section{Tree height estimation}

To simulate the risk of wind damage to a stand, the target model required information such as $\mathrm{H}$, DBH and A. However, the size parameters (e.g. $\mathrm{H}, \mathrm{DBH}$ ) in every patch were not available on the research site. Therefore, the tree height of Acacia hybrid plantations were predicted. The process was divided into two steps: i) estimation of tree height based on the growth curve of Acacia hybrid for the whole of Quang Tri, and ii) definition of a site index (SI) to investigate the difference in site productivity of a smaller region. In the first process, stand height for Acacia plantations was estimated using a tree height growth curve based on the 110 sample plots. The $\mathrm{H}_{\mathrm{dom}}$ was used as the response variable. The dataset was divided into two groups: a training dataset $(70 \%$ of total sample plots) and an evaluation dataset (30\% of total sample plots) in R software (R Core Team 2007). The stand age (based on the plantation year) of Acacia hybrid was from 2 to 16 years. Several differential equations of growth functions 


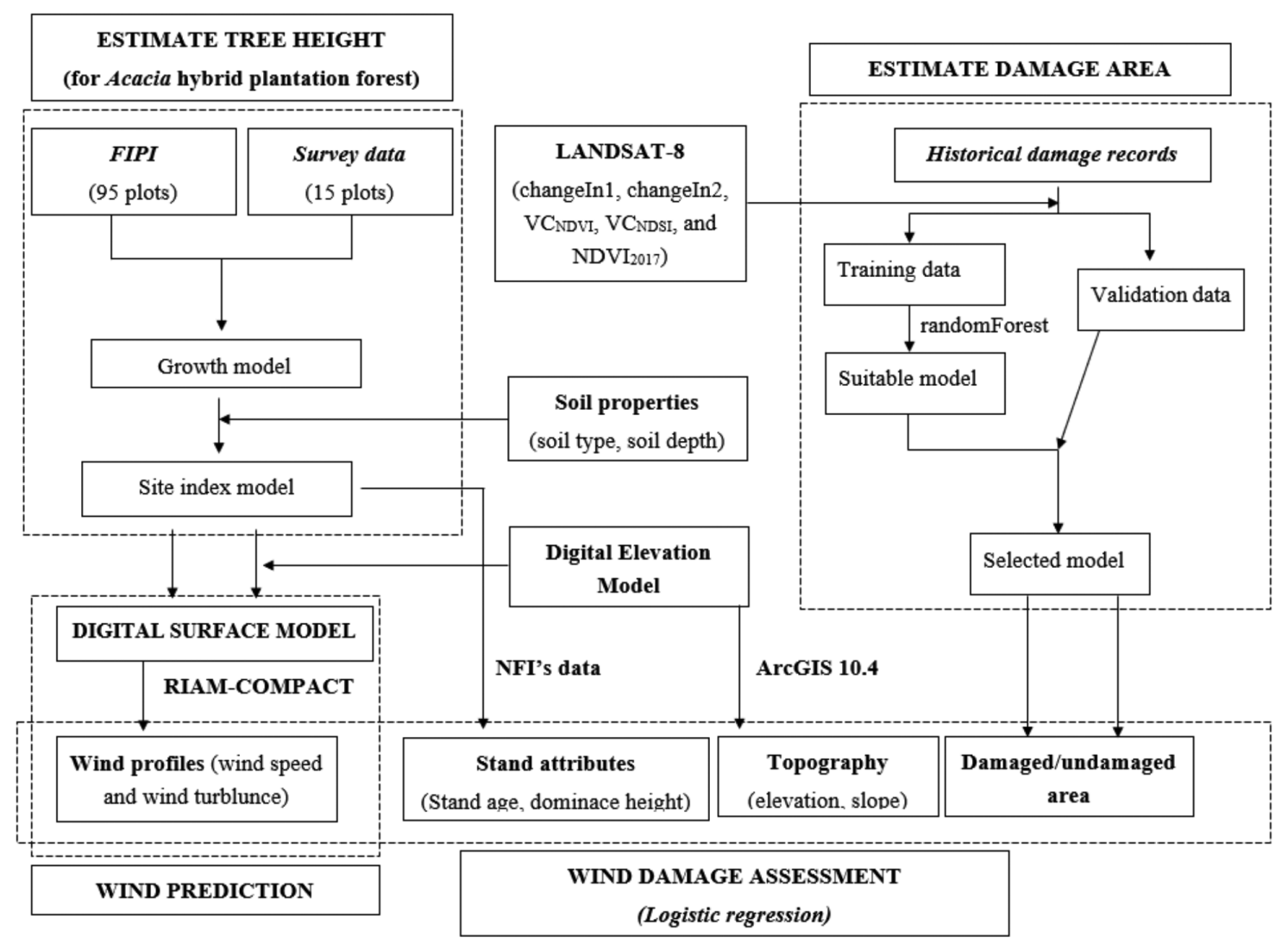

Figure 2 The flowchart describes data processing of the study

were used, as demonstrated in Table 1. Bayesian theory was applied with the 'rstan' package in $\mathrm{R}$ to estimate the parameters of these non-linear equations. The best performance equation was selected based on the Watanabe-Akaike information criterion (WAIC), mean residual (MERS), residual mean of squares (RMS) and accuracy.

In the second process, the SI for each specific stand was calculated directly, based on $\mathrm{H}_{\text {dom }}$ associated with a baseline age $\left(\mathrm{A}_{0}\right)$. All pairs of $\mathrm{H}_{\mathrm{dom}} / \mathrm{A}$ of all sites were selected together and defined the function $\mathrm{H}_{d}=f(A)$, where $A$ is the age of a forest. Therefore, SI was calculated as follows:

$$
\mathrm{SI}=\mathrm{H}_{\mathrm{dom}} \times \mathrm{f}\left(\mathrm{A}_{0}\right) / \mathrm{f}\left(\mathrm{A}_{\mathrm{i}}\right)
$$

where SI is site index, $f(x)$ is the function for estimating tree height at age $\mathrm{x}, \mathrm{A}_{0}$ is the baseline age, and $\mathrm{A}_{i}$ is tree age of a stand.

Then, SI was estimated by investigating the relationship between SI and soil properties (soil type, soil depth), and site conditions using a generalised linear model (GLM) as follows:

Table 1. Growth models used for estimating tree height based on the pairs of dominant height $\left(\mathrm{H}_{\mathrm{dom}}\right)$ /age for Acacia hybrid in the research site

\begin{tabular}{lll}
\hline Designation & Equation & Free parameters \\
\hline Lunqdqvist-Korf & $(1.1) \mathrm{H}=\mathrm{a} \cdot \mathrm{e}^{-\mathrm{b} / \mathrm{T}^{\wedge} \mathrm{c}}$ & $\mathrm{a}, \mathrm{b}, \mathrm{c}$ \\
Shumacher & $(1.2) \mathrm{H}=\mathrm{a} \cdot \mathrm{e}^{-\mathrm{b} \cdot \mathrm{T}^{\wedge} \mathrm{c}}$ & $\mathrm{a}, \mathrm{b}, \mathrm{c}$ \\
Chapman-Richards & $(1.31) \mathrm{H}=\mathrm{a} \cdot\left(1-\mathrm{e}^{-\mathrm{bT}}\right)^{1 /(1-\mathrm{c})}$ & $\mathrm{a}, \mathrm{b}$ \\
& $(1.32) \mathrm{H}=\mathrm{a} \cdot\left(1-\mathrm{e}^{-\mathrm{bT}}\right)^{\mathrm{c}}$ & $\mathrm{c}$ shape of parameter \\
Gompertz & $(1.4) \mathrm{H}=\mathrm{a} \cdot \mathrm{e}^{-\mathrm{b} \cdot \exp (-\mathrm{cT})}$ & $\mathrm{a}, \mathrm{b}, \mathrm{c}$ \\
Hossfield & $(1.5) \mathrm{H}=$ & $\mathrm{a}, \mathrm{b}, \mathrm{c}$ \\
\hline
\end{tabular}

$\mathrm{H}=$ tree height, $\mathrm{a}=$ the asymptote of dominant height $(\mathrm{H}, \mathrm{m}), \mathrm{T}=$ stand age (tree age) 
$\mathrm{SI} \sim \mathrm{a} \times \mathrm{Sty}+\mathrm{b} \times \mathrm{Sde}+\mathrm{c} \times \mathrm{Slo}+\mathrm{d} \times \mathrm{Elv}+\mathrm{e} \times \mathrm{Az}$

where SI = site index, Sty = soil type, $\mathrm{Sde}=$ soild depth, Slo = slope, Elv = elevation and Az = azimuth.

The best model was selected based on the lowest value of the Akaike information criterion (AIC) with decreasing explanatory variables (McGullagh \& Nelder 1989). From the SI (equation 2), the $\mathrm{H}_{\mathrm{dom}}$ was calculated for the stands in the research site (equation 1), with $A_{i}$ and $A_{0}$. Since there was no database for tree cover, e.g. Digital Surface Model (DSM), the DSM was estimated by combining the DEM and vegetation height of all land-use types. Overlay tools in ArcGIS were used for this process. Tree heights of Acacia plantations were calculated using equation 1 , and other heights of land-use and vegetation types were assumed based on the measurement of height for each type, as shown in Appendix 2.

\section{Prediction of wind properties}

Wind speed and wind turbulence were estimated using RIAM-COMPACT (Uchida 2008). The software allows simulation of strong airflow conditions resulting from complex terrain at different levels, using the Large-Eddy Simulation technique. RIAM-COMPACT was used to calculate the mean wind velocity and standard deviation of wind velocity $(\delta)$ at an approximate height of 10 and $15 \mathrm{~m}$ above canopy, respectively, using $30 \times$ $30 \mathrm{~m}$ grid data from DSM topography. A power law of $1 / 7$ of wind profile, an initial wind speed of $10 \mathrm{~ms}^{-1}$, and a buffer zone with a distance of 2.5 $\mathrm{km}$ were used as parameters for the simulation. The estimated velocities for each wind direction were recorded as a mesh size of $100 \times 100 \mathrm{~m}$.

\section{Estimation of wind damaged locations from satellite images}

Using ArcGIS tools, areas covered by water bodies, road and cloudy cover were removed before using them for image classification. The normalised difference vegetation index (NDVI) and normalised difference soil index (NDSI) were used, as presented in equation 3 and 4, extracted from LANDSAT-8. After calculating the NDVI and NDSI for each image, the change vector of NDVI and NDSI $\left(\mathrm{VC}_{\mathrm{NDVI}}\right.$, and $\left.\mathrm{VC}_{\mathrm{NDSI}}\right)$ were defined, in which $\mathrm{VC}_{\mathrm{NDVI}}$ is the change value of $\mathrm{NDVI}$ and $\mathrm{VC}_{\mathrm{NDSI}}$ is the change value of NDSI at the same location in 2017 and 2018, respectively (equation 5 and 6 ):

$$
\begin{aligned}
& \mathrm{NDVI}=\frac{\mathrm{NIR}-\mathrm{RED}}{\mathrm{NIR}+\mathrm{RED}}, \\
& \mathrm{NDSI}=\frac{\text { SWIR }- \text { GREEN }}{\mathrm{SWIR}+\mathrm{GREEN}}, \\
& \mathrm{VC}_{\mathrm{NDVI}}=\mathrm{NDVI}_{2017}-\mathrm{NDVI}_{2018,} \\
& \mathrm{VC}_{\mathrm{NDSI}}=\mathrm{NDSI}_{2018}-\mathrm{NDSI}_{2017},
\end{aligned}
$$

where NIR is band 5 ( $851-879 \mathrm{~nm})$, RED is band $4(636-673 \mathrm{~nm})$, SWIR is band $6(1556-1651 \mathrm{~nm})$ and GREEN is band $3(533-590 \mathrm{~nm})$.

In equation 7 , the changeIn 1 index was used to enhance the difference in forest change compared with others, whereas the changeIn2 index in equation 8 aimed to determine the direction of forest change such as deforestation (if changeIn2 is positive) or growth of vegetation including afforestation (if changeIn2 is negative). The two change index vectors were calculated as follows:

$$
\begin{aligned}
& \text { changeIn } 1=\left(\mathrm{VC}_{\mathrm{NDVI}}{ }^{2}+\mathrm{VC}_{\mathrm{NDSI}}\right)^{1 / 2}, \\
& \text { changeIn } 2=\mathrm{VC}_{\mathrm{NDVI}}+\mathrm{VC}_{\mathrm{NDSI}}
\end{aligned}
$$

The 'randomForest' package in $\mathrm{R}$ was used for building the classification model, in which damage condition (damage or no damage) was the response variable, while the predictor variables were changeIn1, changeIn2, $\mathrm{VC}_{\mathrm{NDVI}}, \mathrm{VC}_{\mathrm{NDSI}}$ and $\mathrm{NDVI}_{2017}$. The $\mathrm{NDVI}_{2017}$ was considered as a predictor variable because a large NDVI value might be sensitive to wind damage, for example, a stand with taller trees (high value of NDVI) will be more susceptible to wind damage than one with shorter trees. The selected model was evaluated through the out-ofbagging error rate $(\mathrm{OOB})$, used for assessing the prediction performance of Random Forest (RF), receiver operating characteristic curve (ROC curve), the area under the ROC curve (AUC) and overall accuracy (Breiman 1996). 
Predicting the wind damage in Acacia hybrid plantations

A logistic regression technique (Collett 2003) was used to assess the probability of wind disturbance. Predictor variables to predict the wind damage probability were calculated using ArcGIS 10.4 Spatial Analyst extension (Table 2) and training models (Table 3). Due to the large difference in the range of their values (e.g. wind speed, turbulence intensity), variables were standardised before adding to the wind damage model.

\section{The effect of soil type on the physical stability of trees for model validation}

Investigation was carried out on the physical stability of Acacia hybrid trees in Linh Thuong, Quang Tri, Vietnam, referred to as soil type $\mathrm{F}_{\mathrm{d}}$ and soil type $\mathrm{F}_{\mathrm{s}}$, located at $16^{\circ} 52^{\prime} \mathrm{N}, 106^{\circ} 52^{\prime} \mathrm{E}$ and $16^{\circ} 53^{\prime} \mathrm{N}, 106^{\circ} 54^{\prime} \mathrm{E}$ of the research site, respectively. Physical stability was measured by tree-pulling experiments in September 2019, to validate the effect of soil type on the resistance to wind damage, predicted in the model. A total of 14 and 16 trees were selected from $F_{d}$ and $F_{s}$, respectively. The sample trees had a wide range of DBH from 8.9 to $22.4 \mathrm{~cm}$. The maximum turning moment $\left(\mathrm{TM}_{\max }\right)$ of trees was measured according to Kamimura et al. 2012.

\section{RESULTS}

\section{Tree height estimation}

Among growth models in Table 1, ChapmanRichards (model 1.31) was the best model with the lowest value of WAIC (389.9) (Appendix 3).
The other five equations were excluded because the posterior interval $(97.5 \%)$ for the model parameters contained both negative and positive values (e.g. the posterior interval for b was -0.52 and 707.92 in model 1.1), or had a higher WAIC value compared to model 1.31 . The validation results indicated that equation 9 was a good model for predicting $\mathrm{H}_{\mathrm{dom}}$, with low values of MERS and RMS and high accuracy $(0.18 \mathrm{~m}, 0.89$ $\mathrm{m}$, and $91 \%$, respectively). The final equation selected for Acacia plantations was as follows:

$$
\mathrm{H}_{\mathrm{dom}}=23.6 \times\left(1-\mathrm{e}^{-0.04 \times A}\right)^{0.51}
$$

Among the three top models used for predicting SI at the baseline age $\left(\mathrm{A}_{0}\right)$ using soil and topographic parameters, model 1.10 had the lowest AIC value, and all the predicted parameters were significant $(\mathrm{p}<0.05)$ (Table 4). This model had an accuracy value of $87.9 \%$ and MERS of $1.03 \mathrm{~m}$ on the validation dataset. The $\mathrm{H}_{\mathrm{dom}}$ map of Acacia plantations in the research site is shown in Appendix 4. The baseline age for the SI curve was defined as 4 years old $\left(\mathrm{A}_{0}\right)$ because the growth rate of Acacia hybrid plantations was stable from 4 to 6 years old, and slow from 7 years old (Sein \& Mitlöhner 2011). Prediction of SI for all forest patches depended on equation 1.

\section{Estimation of wind damaged locations from satellite images}

The model for predicting damaged or undamaged areas was processed only for Acacia hybrid plantations based on their relationship with five factors including changeIn1, changeIn2, $\mathrm{VC}_{\mathrm{NDVI}}, \mathrm{VC}_{\mathrm{NDSI}}$ and $\mathrm{NDVI}_{2017}$. The results of the

Table 2 List of predictor variables participating in the predictive model

\begin{tabular}{llll}
\hline Group factors & Predictor variables & $\begin{array}{l}\text { Original } \\
\text { classification }\end{array}$ & Source \\
\hline Wind profile & Wind speed $(\mathrm{WS})$ & $\begin{array}{l}\text { Continuous } \\
\text { Continuous }\end{array}$ & RIAM-COMPACT \\
& $\mathrm{WS}_{3}=\mathrm{WS}+3 \mathrm{x} \delta$ & RIAM-COMPACT \\
& Turbulence intensity $(\delta / \mathrm{WS})$ & Continuous & RIAM-COMPACT \\
Topography & Elevation $($ Elv $)$ & Continuous & DEM \\
& Slope $($ Slo $)$ & Continuous & DEM \\
\hline Stand attribute & Standage $(\mathrm{A})$ & Integer & NFI \\
& Dominant height $\left(\mathrm{H}_{\mathrm{dom}}\right)$ & Continuous & Prediction from SI \\
& Soil type $($ Sty $)$ & Categorical & NIAPP \\
\hline
\end{tabular}


Table 3. The training model form used for estimating the wind damage probability

\begin{tabular}{cl}
\hline Model & Model form \\
\hline 1.6 & logit $(\mathrm{p}) \sim \mathrm{a}+\mathrm{b} \times \mathrm{A}+\mathrm{c} \times \mathrm{H}_{\mathrm{dom}}+\mathrm{d} \times \mathrm{WS}\left(\mathrm{WS}_{3}\right)$ \\
1.7 & $\operatorname{logit}(\mathrm{p}) \sim \mathrm{a}+\mathrm{b} \times \mathrm{A}+\mathrm{c} \times \mathrm{H}_{\mathrm{dom}}+\mathrm{d} \times$ Turbulence intensity \\
1.8 & $\operatorname{logit}(\mathrm{p}) \sim \mathrm{a}+\mathrm{b} \times \mathrm{A}+\mathrm{c} \times \mathrm{H}_{\mathrm{dom}}+\mathrm{d} \times \mathrm{Elv}+\mathrm{e} \times$ Slo \\
1.9 & $\begin{array}{l}\text { logit }(\mathrm{p}) \sim \mathrm{a}+\mathrm{b} \times \mathrm{A}+\mathrm{c} \times \mathrm{H}_{\mathrm{dom}}+\mathrm{d} \times \mathrm{WS}\left(\mathrm{WS}_{3}\right)+\mathrm{e} \times \text { Turbulence intensity }+ \\
\\
\mathrm{f} \times \mathrm{Elv}+\mathrm{g} \times \mathrm{Slo}\end{array}$ \\
\hline
\end{tabular}

Note: $\mathrm{p}$ is the probability of a stand being disturbed, $\mathrm{a}, \mathrm{b}, \mathrm{c}, \mathrm{d}, \mathrm{e}, \mathrm{f}, \mathrm{g}$ are the parameters of the model; $\mathrm{H}_{\mathrm{dom}}$ - dominant height, WS = wind speed, Elv - elevation, Slo = slope

Table 4 Estimated parameters and standard error (SE) of multiple regression models for the site index of 4-year-old Acacia plantations (only the models with the three lowest AIC values are shown)

\begin{tabular}{|c|c|c|c|c|c|c|c|c|c|}
\hline \multirow[t]{2}{*}{ Factors } & \multicolumn{2}{|c|}{$\begin{array}{c}\text { Model } 1.10 \\
(\mathrm{AIC}=283.3)\end{array}$} & \multicolumn{4}{|c|}{$\begin{array}{c}\text { Model } 1.11 \\
(\mathrm{AIC}=285.0)\end{array}$} & \multicolumn{3}{|c|}{$\begin{array}{c}\text { Model } 1.12 \\
(\mathrm{AIC}=285.3)\end{array}$} \\
\hline & Estimate & SE & & Estimate & $\mathrm{SE}$ & & Estimate & $\mathrm{SE}$ & \\
\hline Sty C & 5.21 & 0.44 & $* * *$ & 5.17 & 0.45 & $* * *$ & 5.18 & 0.45 & $* * *$ \\
\hline Sty Fa & 8.44 & 0.60 & $* * *$ & 8.11 & 0.70 & $* * *$ & 7.78 & 1.03 & $* * *$ \\
\hline Sty Fe & 6.88 & 0.90 & $* * *$ & 6.41 & 1.03 & $* * *$ & 6.76 & 0.92 & $* * *$ \\
\hline Sty Fl & 12.16 & 1.28 & $* * *$ & 12.04 & 1.29 & $* * *$ & 12.15 & 1.29 & $* * *$ \\
\hline Sty $\mathrm{Fj}$ & 7.08 & 0.80 & $* * *$ & 6.46 & 1.03 & $* * *$ & 6.59 & 1.02 & $* * *$ \\
\hline Sty Fk & 6.33 & 1.28 & $* * *$ & 5.87 & 1.37 & $* * *$ & 5.75 & 1.48 & $* * *$ \\
\hline Sty Fd & 6.85 & 0.74 & $* * *$ & 6.61 & 0.78 & $* * *$ & 6.66 & 0.77 & $* * *$ \\
\hline Sty Fs & 7.14 & 0.57 & $* * *$ & 7.06 & 0.58 & $* * *$ & 7.08 & 0.58 & $* * *$ \\
\hline Sty $\mathrm{Pb}$ & 6.35 & 1.28 & $* * *$ & 6.32 & 1.29 & $* * *$ & 6.35 & 1.29 & $* * *$ \\
\hline Sty Pg & 8.51 & 0.71 & $* * *$ & 8.49 & 0.71 & $* * *$ & 8.49 & 0.71 & $* * *$ \\
\hline Sde & 2.20 & 0.60 & $* * *$ & 2.10 & 0.61 & $* * *$ & 2.18 & 0.60 & $* * *$ \\
\hline Slo & - & - & - & 0.03 & 0.03 & & - & - & - \\
\hline Elv & - & - & - & - & - & & 0.15 & 0.19 & \\
\hline
\end{tabular}

Confidence level: $* * *=0.001, * *=0.01, *=0.05$; Model 1.10: SI $\sim \mathrm{a} \times$ Sty $+\mathrm{b} \times$ Sde, Model 1.11: SI $\sim \mathrm{a} \times$ Sty $+\mathrm{b} \times$ Slo, Model 1.12: SI $\sim \mathrm{a} \times$ Sty $+\mathrm{b} \times$ Elv

model showed that the selected model had an estimated OBB of $1.89 \%$, with number of trees (ntree) set at 100, and value of variables at each split (mtry) of 1 . The overall accuracy and kappa index of the predicted model were $95.83 \%$ and 0.88 , respectively. The model had a high AUC value (0.96) (Figure 3b), which indicated good discrimination between damaged and undamaged points (Hosmer \& Lemeshow 2000). Table 5 indicates a confusion matrix as a tool to evaluate the final RF model. Therefore, this model was able to predict damaged areas, and thus it was suitable as reference data in the next steps. The three highest values of both indices (mean decrease in accuracy and Gini index) were those of $\mathrm{VC}_{\mathrm{NDVI}}$, changeIn 1 and changeIn2 (Figure 3a). The distribution of damaged and undamaged points in the validation set, as a result of image classification for Acacia hybrid in the research site, is shown in Appendix 5.

\section{Wind damage probability model}

The final model for predicting wind damage risk, selected using the lowest AIC value, included the variables $\mathrm{Sty}, \mathrm{A}, \mathrm{H}_{\mathrm{dom}}, \mathrm{WS}_{3}$, Elv and Slo (Appendix $6)$. In this model, $\mathrm{WS}_{3}$ was calculated as the wind direction from south to north, and the height at 
$15 \mathrm{~m}$ above the canopy (Appendix 7). The model showed that $\mathrm{H}_{\text {dom }}, \mathrm{WS}_{3}$ and Slo were associated with high damage probabilities, whereas stand age and elevation seemed to be less susceptible (Table 6). Stands growing on soil type $\mathrm{F}_{\mathrm{s}}$ were more likely to be stable against wind damage than those on soil type $\mathrm{F}_{\mathrm{d}}$ (there was a significant difference, between the two soil types, $\mathrm{p}<0.5$ ). In comparison with other explanatory variables, wind speed $\left(\mathrm{WS}_{3}\right)$ was less important, with the lowest overall importance value of 1.68. Since it had the lowest AIC value, the south direction was considered to be the wind flow direction, which was used for predicting wind speed when validating the final model.

\section{DISCUSSION}

The variable $\mathrm{H}_{\text {dom }}$ was applied to create the growth curve and SI because $\mathrm{H}_{\text {dom }}$ is stable and

Table 5 Results in cross-validation using training data to assess the accuracy of the RF model

\begin{tabular}{llcc}
\hline \multirow{2}{n}{} & & \multicolumn{2}{c}{ Prediction } \\
\cline { 3 - 4 } & & Damaged & Undamaged \\
\hline \multirow{2}{*}{ Reference data } & Damaged & 18 & 0 \\
& Undamaged & 1 & 5 \\
\hline
\end{tabular}

a)
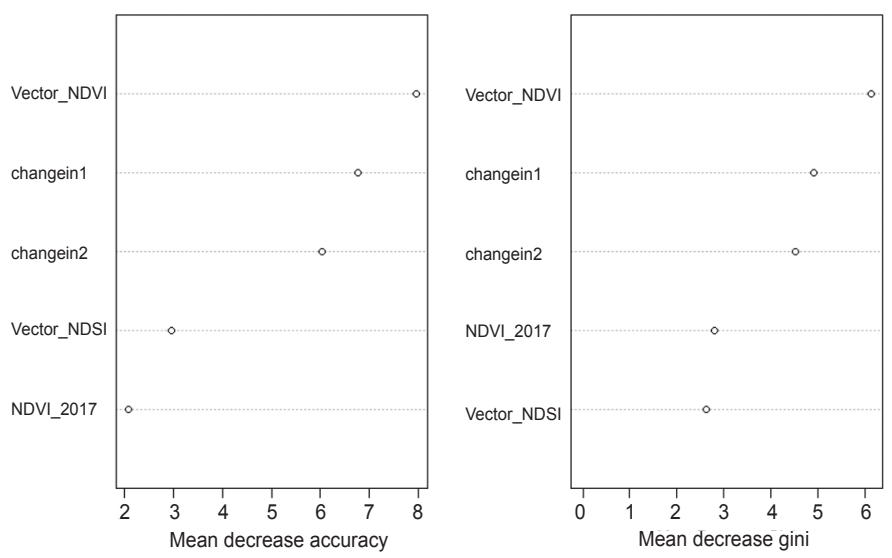

ROC curve

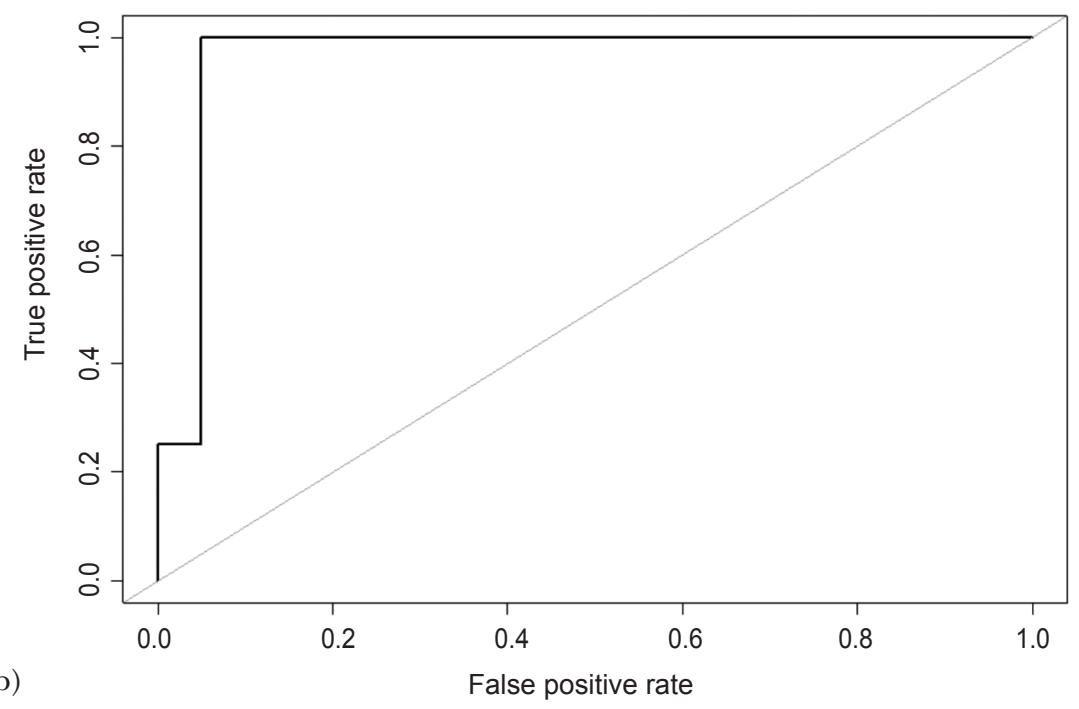

Figure 3 The importance of variables (a) and ROC curves (b) of the model created using Random Forest algorithm 
Table 6 Estimated model coefficients of the generalised linear model for the probability of occurrence of wind damage

\begin{tabular}{lccc}
\hline \multirow{2}{*}{ Explanatory variable } & \multicolumn{3}{c}{ Height above canopy at $15 \mathrm{~m}(\mathrm{AIC}=309.66)$} \\
\cline { 2 - 4 } (Intercept) & Coefficient & SE & Significance \\
Sty F $_{\mathrm{s}}{ }^{\mathrm{N}}$ & 8.869 & 2.946 & $0.003^{* *}$ \\
$\mathrm{~A}$ & -0.809 & 0.334 & $0.015^{*}$ \\
$\mathrm{H}_{\text {dom }}$ & -0.919 & 0.329 & $0.005^{* *}$ \\
$\mathrm{WS}_{3}$ & 3.009 & 1.050 & $0.004^{* *}$ \\
Slo & 0.252 & 0.152 & 0.097. \\
Ele & 0.043 & 0.021 & $0.044^{*}$ \\
\hline
\end{tabular}

\$: soil type $\mathrm{F}_{\mathrm{d}}$ was used as the basis for comparison; confidence level: *** = $0.001, * *=0.01, *=0.05, '$ ' $=0.1$

not dependent on silviculture, e.g., thinning (Burkhart \& Tomes 2012, Beadle et al. 2013). This study on the growth of Acacia hybrid plantation stands confirmed that the ChapmanRichards equation had a good performance for growth curve. Krisnawati et al. (2010) concluded that the Chapman-Richards function is one of the most appropriate equations to establish a growth yield table for forest trees. Several growth models and yield tables have been developed for the whole of Vietnam, however, they require adjustment when applied at a specific locations (Hung et al. 2016). The current study provides a detailed height growth curve and SI, adapted to the current forest management of the research site.

Change vector analysis has been widely used to study the spatio-temporal dynamics of land cover (Sangpradid et al. 2018). By examining five components extracted from the LANDSAT 8 images, the study provided a good qualitative classification for estimating damaged or undamaged areas, with high overall accuracy $(95.83 \%)$ and kappa index (0.88). Factors that often cause error in the image classification process were excluded, such as logging, forest disease and forest fire, as there were no records of these occurrences at the research site according to reports by PFD and the local government. Only one forest patch (no. 592) was excluded because more than $50 \%$ was damaged by typhoons.

Using the classification methods to integrate image information from multi-spectral bands and components of indexes often results in higher accuracy and less bias, compared to using a single band. This is because the feature characteristics in different wavebands can be reflected more realistically (Hichri et al. 2013). In the current findings, $\mathrm{VC}_{\mathrm{NDVI}}$ had the greatest effect on mean decrease, in accuracy measure (Figure 3a), followed by changeIn 1 and changeIn2. This finding is in agreement with Polykretis (2020) who applied change vector analysis to detect landuse change, and found that the most accurate outputs were obtained from the combination of NDVI. The results from image classification, therefore, meet the aim of detecting damaged or undamaged areas caused by the typhoon.

Classification performance tests showed that the wind damage probability model performed moderately well. The model results indicated a higher probability of wind disturbance for taller trees/stands, higher wind speeds, and forests on higher slopes. The inclusion of stand age had a negative effect on damage probability $(\mathrm{p}<0.05)$. Acacia hybrid has rapid growth in height during the early stage, and slows down with maturity (Kha et al. 2012). Thus, older trees naturally have lower slender $(\mathrm{H} / \mathrm{DBH})$. Increasing stand age, therefore, may lead to a decrease in wind damage because of the decline in $\mathrm{H} / \mathrm{DBH}$ (Gardiner et al. 2013). The results showed that taller stands (tree height) were more likely sensitive to wind damage $(p<0.05)$. If a tree is taller, it is more likely to fall over because it is less stable (Dhubhain et al. 2001). In the current study, $H_{\text {dom }}$ was selected instead of the mean tree height of a stand because the highest trees are more susceptible to wind-induced damage. Gardiner (2013) reported that height (in particular, dominant height) was better than other factors as a measure of wind vulnerability. 
The current study found a significant wind speed predictor $\left(\mathrm{WS}_{3}\right.$ at $15 \mathrm{~m}$ high above canopy), with increasing $\mathrm{WS}_{3}$ leading to a greater probability of wind damage. Higher wind speed causes more damage in a stand (Schindler et al. 2012). Thus, $\mathrm{WS}_{3}$ has two functions: i) it represents maximum wind speed within a period, and thus, indicates the maximum force of high wind speed acting on a stand, and ii) it contains standard deviation of wind speed, therefore, illustrating fluctuations in wind velocity or wind turbulence. The results concurred with the findings of Uchida (2008), in which the forest stands were damaged not only by wind speed enhanced by terrain conditions, but also by the fluctuations in wind velocity. The most suitable wind direction was found to be from the south. This agrees with the records of wind direction provided by Dong Ha meteorological station $(\sim 30 \mathrm{~km}$ from the research site).

Concerning soil type, the results showed that the stands on $\mathrm{F}_{\mathrm{s}}$ were more likely to be stable in a tropical storm than those on $\mathrm{F}_{\mathrm{d}}(\mathrm{p}<0.05)$. Soil conditions and soil types are known to be the primary factor affecting root plate stability (Gardiner et al. 2000, Kamimura et al. 2012). To validate the model result on the effect of soil type, the physical stability $\mathrm{TM}_{\max }$ of Acacia hybrid were compared on both soil types. The data analysis revealed that $\mathrm{TM}_{\max }$ in the model of tree failure was governed by tree size (squared $\mathrm{DBH}$ multiplied by $\mathrm{H}$ ) and soil type, and the stability of trees in $\mathrm{F}_{\mathrm{d}}$ was smaller than those in $\mathrm{F}_{\mathrm{s}}$ with the same tree size (Figure 4 ). Therefore, the effect of soil type on modeling forest wind damage was supported by this mechanistic measurement. The coincidence of the statistical model from satellite image with mechanistic measurement suggested the effectiveness of the model as the evaluating factors related to the wind damage.

\section{CONGLUSION}

The current study analysed the wind damage probability in a complex terrain for Acacia hybrid plantation forests in Vietnam by integrating an aerodynamics model for simulating wind speed, wind disturbance records and GIS data. Based on the survey information of wind damage caused by Typhoon Doksuri in 2017, the wind damage probability was estimated at landscape level. The results showed that the wind hazard ratio of Acacia hybrid plantations was associated with stand characteristics (stand age, stand height and soil type), wind velocity, and topographic characteristics (elevation, slope). Higher damage probabilities were found in stands with taller tree height, on higher slopes, and with higher wind speed. The combination of GIS, satellite images and a wind condition prediction model enabled to analyse wind damage prediction concerning stand and topography. Another finding in the current study showed that the pulling experiment gave clear evidence of the effect of soil type on wind risk model. The government of Vietnam aims to prolong the rotation of Acacia hybrid plantations to provide $\log$ and saw wood, which requires a long prediction associated with strong wind events, especially tropical storms and typhoons. The results on the effect of stand age and stand height on the model of wind risk were important findings to establish suitable models for this purpose.

\section{ACKNOWLEDGEMENT}

The authors are grateful to the forest rangers of FPD Quang Tri and staff of the local government for their kind support in the field survey and interviews, as well as to the Faculty of Agriculture, Shizuoka University for funding support for the pulling experiment in September 2019. The authors would like to thank the students of the Silviculture Laboratory for their help in the statistical approach and their support towards the experiment. The authors also thank Leonie Seabrook from Edanz Group for editing the manuscript.

\section{REFERENCE}

Beadle Cl, Trieu DT \& Harwood C. 2013. Thinning increases saw-log values in fast-growing plantations of Acacia hybrid in Vietnam. Journal of Tropical Forest Science 25: 42-51.

BREIMAN L. 1996. Bagging predictors. Mach Learn 24:123-140. doi: 10.1023/A:1018054314350.

Burkhart HE \& Tomé M. 2012. Modeling Forest Trees and Stands. Springer Netherlands. doi: 10.1007/978-90481-3170-9.

Chirici G, Bottalico F, Giannetti F et al. 2018. Assessing forest windthrow damage using single-date, postevent airborne laser scanning data. Forestry 91: 27-37. doi:10.1093/forestry/cpx029.

Collett D. 2003. Modeling Binary Data (2 ${ }^{\text {nd }}$ edition). Chapman and Hall, London. https:/ / doi.org/10.1201/b16654. 
Dhubhárn A, Walshe J, Bulfin M. ET Al. 2001. The initial development of a windthrow risk model for Sitka spruce in Ireland. Forestry 74: 161-170. doi: 10.1093/ forestry/74.2.161.

Do TV. 2020. Fine-root vertical profile, production, mortality and decomposition in an acacia plantation in north-east Vietnam. Journal of Tropical Forest Science 32: 296-304. doi:10.2307/26921877.

EsRI. 2003. ArcGIS: Working with Geodatabase Topology - An ESRI White Paper. ESRI Press, Redland, CA.

Gardiner B \& Quine C. 2000. Management of forests to reduce the risk of abiotic damage - a review with particular reference to the effects of strong winds. Forest Ecology and Management 135: 261-277. doi: 10.1016/S0378-1127(00)00285-1.

Gardiner B, Schuck A, SchelhaAs MJ et Al. 2013. Living with Storm Damage to Forests. European Forest Institute, Joensuu.

Hichri H, Bazi Y, Alajlan N \& Malek S. 2013. Interactive segmentation for change detection in multispectral remote-sensing images. IEEE Geoscience $\mathcal{E}$ Remote Sensing Letters 10): 298-302. doi:10.1109/ LGRS.2012.2204953.

Hosmer DW \& Lemeshow S. 2000. Applied Logistic Regression ( $2^{\text {nd }}$ edition). John Wiley \& Sons Inc., New York. doi:10.1002/0471722146.

Hung T, Almeida A, Eyles A \& Mohammed C.2016. Predicting productivity of Acacia hybrid plantations for a range of climates and soils in Vietnam. Forest Ecology and Management 367: 97-111. doi:10.1016/j. foreco.2016.02.030.

Kamimura K \& Shiraishi NA. 2007. Review of strategies for wind damage assessment in Japanese forests. Journal of Forest Research 12: 162-176. https://doi. org/10.1007/s10310-007-0005-0.

Kamimura K, Kitagawa K, Saito S \& Mizunaga H. 2012. Root anchorage of hinoki (Chamaecyparis obtuse Sieb. Et Zucc. Endl.) under the combined loading of wind and rapidly supplied water on soil: analyses based on tree-pulling experiments. European Journal of Forest Research 131: 219 - 227. doi: 10.1093/forestry/ cpt011.

Kamimura K, Saito S, KinoshitA S et al. 2013. Analysis of wind damage caused by multiple tropical storm events in Japanese Cryptomeria japonica forests. Forestry: An International Journal of Forest Research 86: 411-420. https://doi.org/10.1093/forestry/cpt011.

Kha LD, Harwood C ET AL. 2012. Growth and wood basic density of Acacia hybrid clones at three locations in Vietnam. New Forests 43: 13-19. doi: 10.1007/ s11056-011-9263-y.

Krisnawati H, Wang Y \& Ades P. 2010. Generalized Height-Diameter Models for Acacia mangium willd. Plantations in South Sumatra. Indonesian Journal of Forestry Research 7: 1-19. doi:10.20886/ijfr.2010.7.1.
Mcgullagh P \& Nelder JA. 1989. Generalized Linear Models ( $2^{\text {nd }}$ edition). Chapman and Hall, London. http:// dx.doi.org/10.1007/978-1-4899-3242-6.

MrtchelL SJ. 2013. Wind as a natural disturbance agent in forest: a systhesis. Forestry 86: 147-157. https://doi. org/10.1093/forestry/cps058.

Nguyen P, Sellars S, Thorstensen A et al. 2014. Satellites track precipitation of super Typhoon Haiyan. Eos, Transactions American Geophysical Union 95: 133-135. doi:10.1002/2014eo160002.

Peltola H, Kellomaki S, Vaisanen H \& Ikonen V. 1999. A mechanistic model for assessing the risk of wind and snow damage to single trees and stands of Scots pine, Norway spruce and birch. Canadian Journal of Forest Research 29: 647-661. doi: 10.1139/x99-029.

Polykretis C, Grillakis M \& Alexakis D. 2020. Exploring the impact of various spectral indices on land cover change detection using change vector analysis: a case study of Crete island, Greece. Remote Sensing 12: 319. doi: $10.3390 /$ rs12020319.

R CORE TEAM. 2018. R: A Language and Environment for Statistical Computing. R Foundation for Statistical Computing, Vienna. https://www.R-project.org/.

SANGPRADID S. 2018. Change vector analysis using integrated vegetation indices for land cover change detection. International Journal of Geoinformatics 14: 71-77.

Schindler D, Bauhus J \& Mayer H. 2012. Wind effects on trees. European Journal of Forest Research 131: 159-163. doi:10.1007/s10342-011-0582-5.

Seidl R, Spies TA, Peterson DL et al. 2016. Searching for resilience: addressing the impacts of changing disturbance regimes on forest ecosystem services. The Journal of applied ecology 53: 120-129. https:/ / doi. org/10.1111/1365-2664.12511.

Sein CC \& Mitlöhner R. 2011. Acacia hybrid: Ecology and silviculture in Vietnam. Center for International Forestry Research, Bogor.

UCHIDA T \& OHYA Y. 2008. Micro-siting technique for wind turbine generators by using large-eddy simulation. Journal of Wind Engineering and Industrial Aerodynamics 96: 2121-2138. https://doi.org/10.1016/j. jweia.2008.02.047.

Valinger E \& Fridman J. 2011. Factors affecting the probability of windthrow at stand level as a result of Gudrun winter storm in southern Sweden. Forest Ecology and Management 262: 398-403. doi:10.1016/j. foreco.2011.04.004.

Wang C, Liang J \& Hodges KI. 2017. Projections of tropical cyclones affecting Vietnam under climate change: downscaled HadGEM2-ES using PRECIS 2.1. Quarterly Journal of the Royal Meteorological Society 143: 1844-1859. https://doi.org/10.1002/qj.3046. 
Appendix 1 The LANDSAT-08 image's properties in the study

\begin{tabular}{lll}
\hline & Before Doksuri occurred & After Doksuri occurred \\
\hline Sensor & OLI/TIRS combined & OLI/TIRS combined \\
Satellite & 08 & 08 \\
Processing correction level & L1TP - terrain precision correction & L1TP - terrain precision correction \\
Path & 125 & 125 \\
Row & 048 & 048 \\
Acquisition time & $2017 / 06 / 06$ & $2018 / 04 / 22$ \\
Processing time & $2017 / 06 / 16$ & $2018 / 05 / 02$ \\
Collection number & 01 & 01 \\
Collection category & Tier 1 & Tier 1 \\
Total bands & 11 & 11 \\
Resolution & 30 meters for bands 1 to 7,9 & 30 meters for bands 1 to 7,9 \\
& 15 meters for bands 8 & 15 meters for bands 8 \\
Sence size & 100 meters for band 10,11 & 100 meters for band 10,11 \\
\hline
\end{tabular}

Appendix 2 Height for vegetation and land-use types in the research site

\begin{tabular}{lcl}
\hline Covered types & Height $(\mathrm{m})$ & Note \\
\hline Other lands & 4 & Construction, house \\
Bare land type A & 2 & Bare land with a small brush \\
Bare land type B & 8 & Bare land with shrub and bamboo \\
New plantation & 3 & New planting forest within 1 year \\
Water face & 0 & River, pond, or lake \\
Agriculture & 3 & Farm or crop \\
Natural forest (poor) & 15 & Poor volume stocks \\
Natural forest (medium) & 20 & Medium volume stocks \\
Natural forest (rich) & 23 & Rich volume stocks \\
\hline Other forest plantation & 18 & \\
- Pinus (age of 14) & 14 & Planted area covered by Pinus caribea \\
- Rubber (age of 15) & & Planted area covered by Hevea brasiliensis \\
\hline
\end{tabular}


Appendix 3 Parameter estimation for six growth models approaching Bayesian interference respecting to Acacia plantation in the study area

\begin{tabular}{|c|c|c|c|c|c|c|}
\hline Equation forms & Parameter & Mean & $2.5 \%$ & $50 \%$ & $97.5 \%$ & rhat \\
\hline \multirow[t]{3}{*}{$(1.1)$} & $\mathrm{a}$ & $4.31 E+307$ & 3.54 & $2.93 \mathrm{E}+307$ & $1.342909 \mathrm{e}+308$ & $\mathrm{NaN}$ \\
\hline & $\mathrm{b}$ & 471.16 & -0.52 & 706.41 & 707.92 & 426.25 \\
\hline & c & -0.24 & -1.01 & 0 & 0 & 3.23 \\
\hline \multirow{3}{*}{$\begin{array}{l}(1.2) \\
\text { WAIC = 588.5 }\end{array}$} & $\mathrm{a}$ & $7.62 \mathrm{E}+307$ & $3.84 \mathrm{E}+306$ & $7.22 \mathrm{E}+307$ & $1.67 \mathrm{e}+308$ & $\mathrm{NaN}$ \\
\hline & b & 481.95 & 22.6 & 706.55 & 708.03 & 108.02 \\
\hline & c & 5.9 & 0 & 0 & 24.4 & 3.48 \\
\hline \multirow{3}{*}{$\begin{array}{l}(1.31) \\
\text { WAIC }=389.9\end{array}$} & $\mathrm{a}$ & 23.6 & 16.07 & 23.18 & 32.41 & 1.08 \\
\hline & $\mathrm{b}$ & -0.04 & -0.13 & -0.03 & -0.01 & 1.03 \\
\hline & $\mathrm{c}$ & -1.04 & -1.5 & -1.06 & -0.44 & 1.04 \\
\hline \multirow{3}{*}{$\begin{array}{l}(1.32) \\
\text { WAIC }=392.1\end{array}$} & $\mathrm{a}$ & 22.77 & 15.62 & 22.35 & 32.8 & 1.03 \\
\hline & b & -0.05 & -0.16 & -0.04 & -0.01 & 1.01 \\
\hline & c & 0.52 & 0.4 & 0.5 & 0.77 & 1.01 \\
\hline \multirow[t]{3}{*}{ (1.4) } & $\mathrm{a}$ & $4.64 \mathrm{e}+307$ & $1.04 \mathrm{e}+01$ & $3.44 \mathrm{e}+307$ & $1.54 \mathrm{e}+308$ & $\mathrm{NaN}$ \\
\hline & $\mathrm{b}$ & $1.71 \mathrm{e}+17$ & $-1.25 \mathrm{E}+17$ & $7.07 e+02$ & $1.26 \mathrm{e}+18$ & 3.07 \\
\hline & c & $3.87 e+16$ & 0.00 & 0.00 & $2.62 e+17$ & 1.61 \\
\hline \multirow[t]{3}{*}{ (1.5) } & a & $3.27 \mathrm{e}+307$ & 0.01 & 743.19 & $1.66 \mathrm{e}+308$ & $\mathrm{NaN}$ \\
\hline & b & -7.84 & -203.06 & 0.21 & 135.86 & 2.33 \\
\hline & c & -54.94 & -188.52 & -21.66 & 4.45 & 4.41 \\
\hline
\end{tabular}

Note: rhat is the potential scale reduction factor on split chains

Appendix 4 The $\mathrm{H}_{\mathrm{dom}}$ of Acacia hybrid plantation forest (referred to SI) in the research site

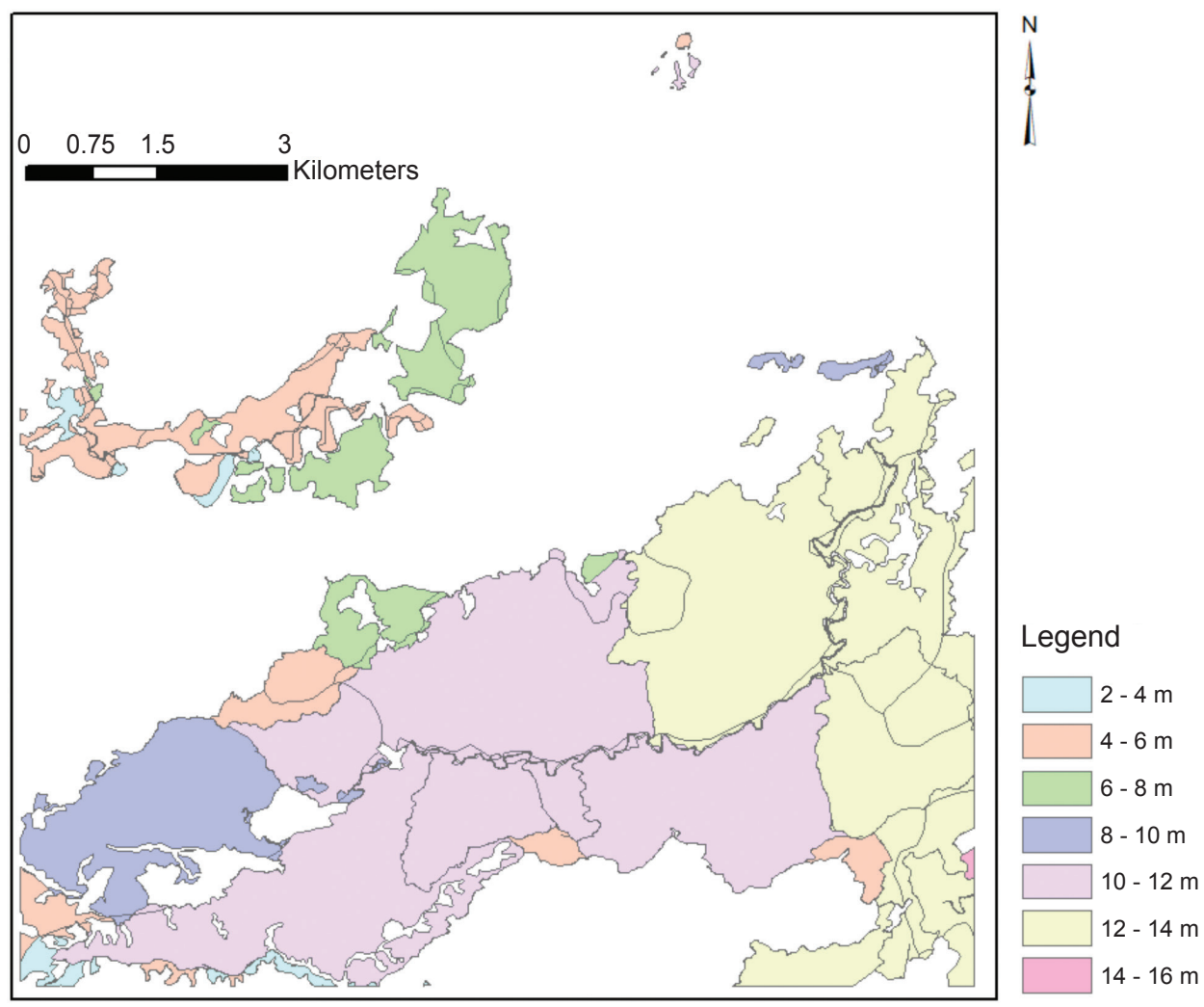


Appendix 5 The distribution of damaged and undamaged points in the validation dataset

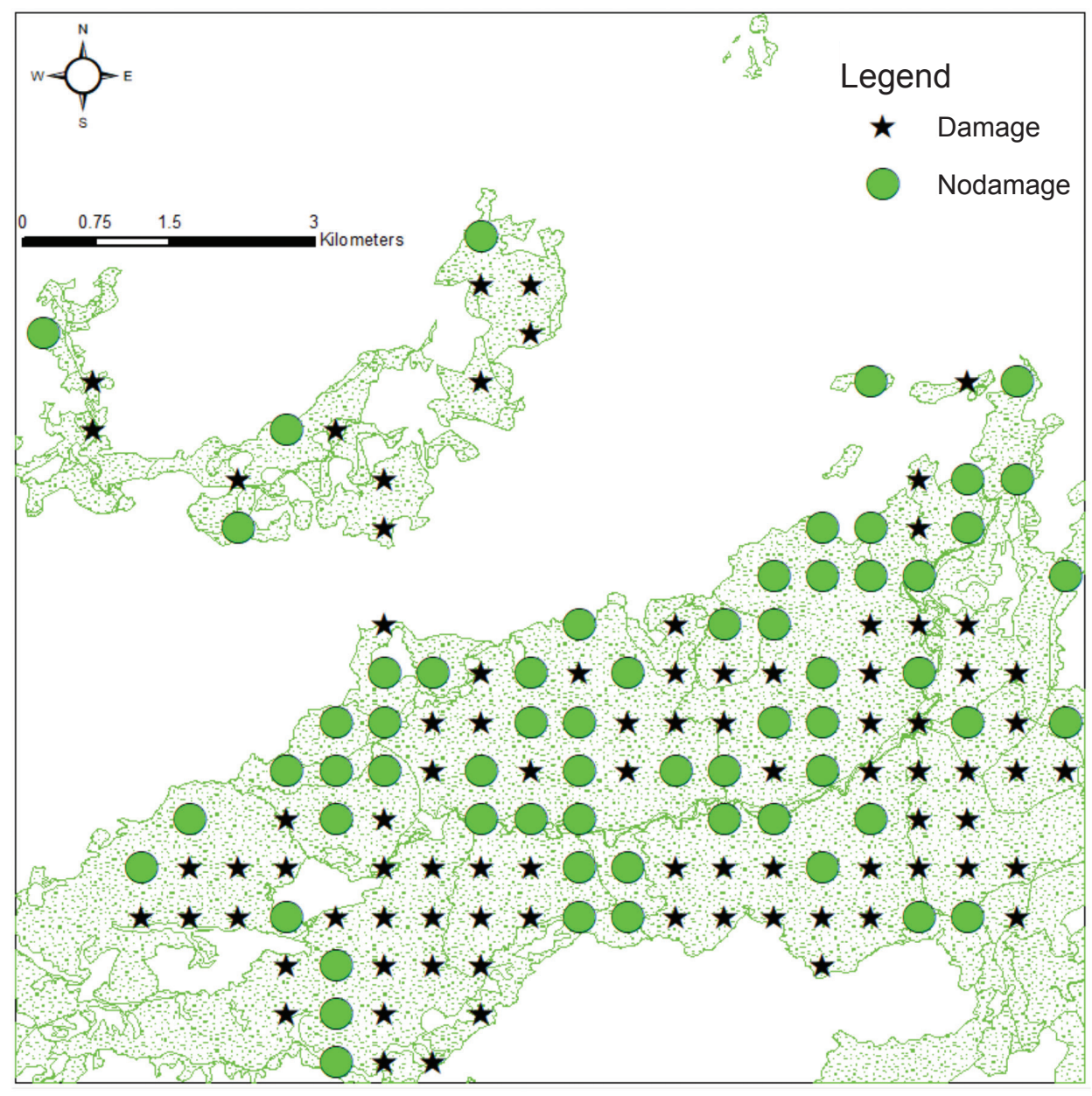

Appendix 6 Akaike information criterion (AIC) for predicting wind damage probability with wind direction from south to north at $15 \mathrm{~m}$ above the canopy

\begin{tabular}{clc}
\hline Model & Model form & AIC \\
\hline 1.6 & $\operatorname{logit}(\mathrm{p}) \sim \mathrm{a}+\mathrm{b} \times \mathrm{A}+\mathrm{c} \times \mathrm{H}_{\text {dom }}+\mathrm{d} \times \mathrm{WS}_{3}$ & 315.59 \\
1.7 & $\operatorname{logit}(\mathrm{p}) \sim \mathrm{a}+\mathrm{b} \times \mathrm{A}+\mathrm{c} \times \mathrm{H}_{\mathrm{dom}}+\mathrm{d} \times$ turblence intensity & 316.92 \\
1.8 & $\operatorname{logit}(\mathrm{p}) \sim \mathrm{a}+\mathrm{b} \times \mathrm{A}+\mathrm{c} \times \mathrm{H}_{\mathrm{dom}}+\mathrm{d} \times$ Elv $+\mathrm{e} \times$ Slo & 310.07 \\
1.9 & $\operatorname{logit}(\mathrm{p}) \sim \mathrm{a}+\mathrm{b} \times \mathrm{A}+\mathrm{c} \times \mathrm{H}_{\mathrm{dom}}+\mathrm{e} \times$ turblence intensity $+\mathrm{f} \times \mathrm{Elv}+\mathrm{g} \times$ Slo & 311.14 \\
1.9 & $\operatorname{logit}(\mathrm{p}) \sim \mathrm{a}+\mathrm{b} \times \mathrm{A}+\mathrm{c} \times \mathrm{H}_{\text {dom }}+\mathrm{d} \times \mathrm{WS}_{3}+\mathrm{f} \times$ Elv $+\mathrm{g} \times$ Slo & 309.67 \\
1.9 & $\operatorname{logit}(\mathrm{p}) \sim \mathrm{a}+\mathrm{b} \times \mathrm{A}+\mathrm{c} \times \mathrm{H}_{\text {dom }}+\mathrm{d} \times \mathrm{WS}_{3}+\mathrm{e} \times$ turblence intensity $+\mathrm{f} \times$ Elv $+\mathrm{g} \times$ Slo & 311.04 \\
\hline
\end{tabular}

$\mathrm{H}_{\mathrm{dom}}=$ dominant height; $\mathrm{WS}_{3}=$ wind speed, Elv = elevation, Slo = slope; $\mathrm{p}$ is the probability of a stand being disturbed, a, b, c, d, e, f, g are the parameters of the model 
Appendix 7 Wind speed distribution from south to north predicted by RIAM-COMPACT at $15 \mathrm{~m}$ above the canopy

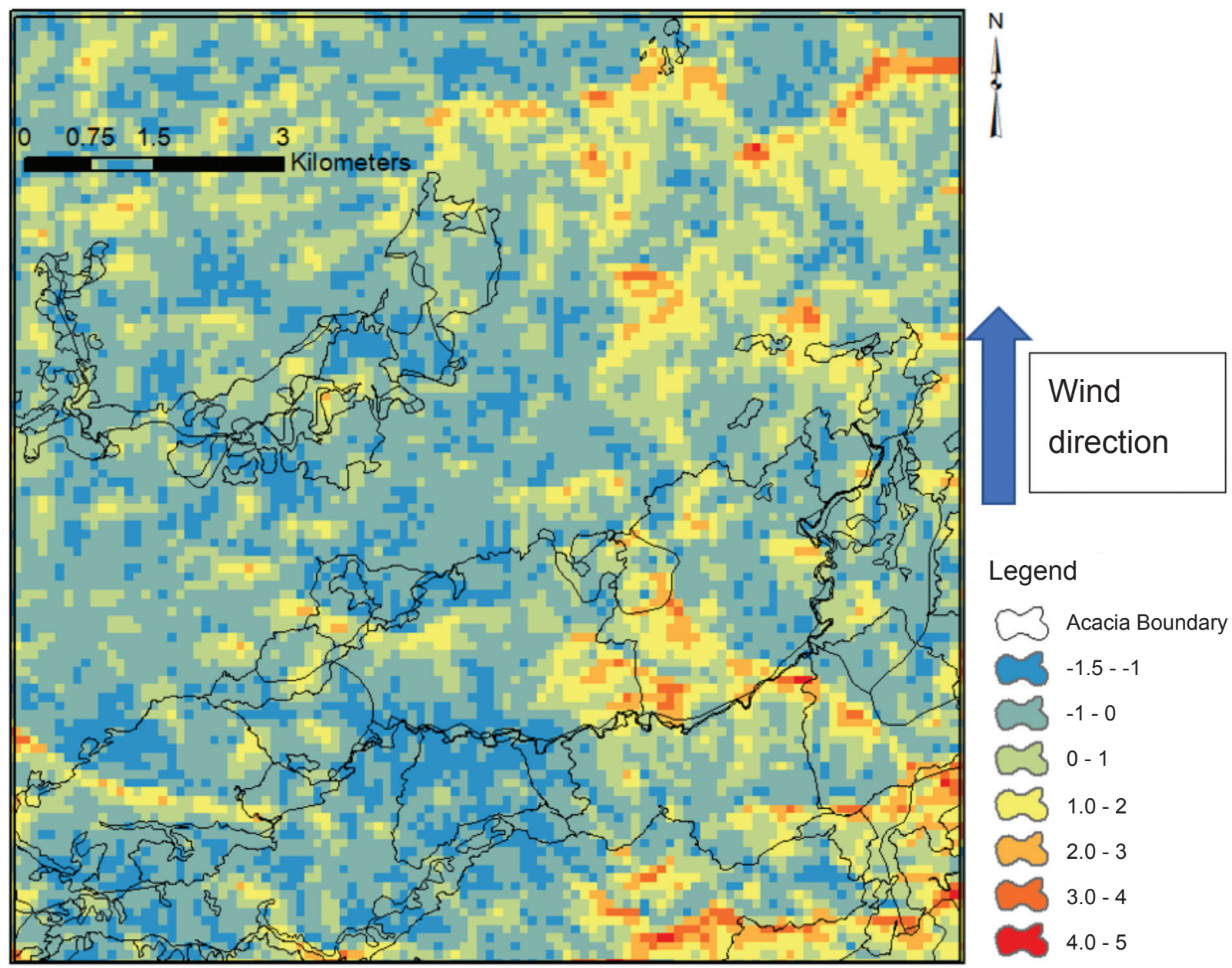

